\title{
Heterotopic pancreatic tissue in the gallbladder
}

\author{
Shashi P. Sharma, MBBS, MD, Shahzada K. Sohail, MBBS, FCPS, Salah Makkawi, MBBS, DIS, Emadeldein Abdalla, MBBS, MMSCP.
}

\begin{abstract}

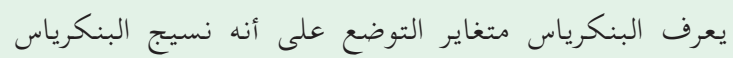

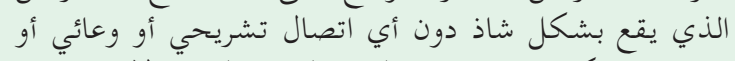

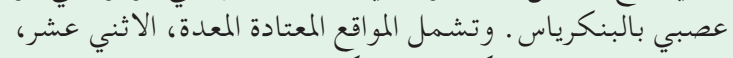

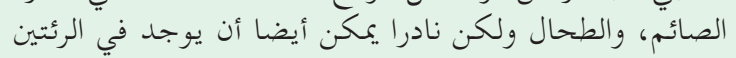

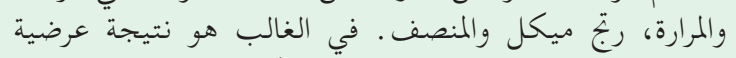

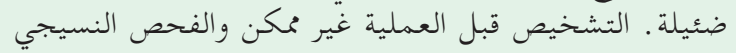

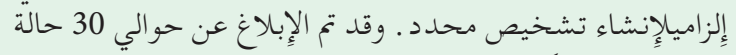

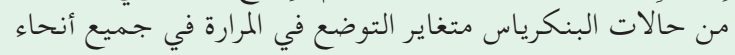

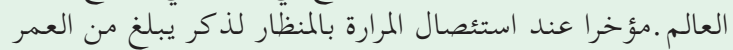

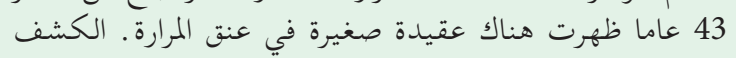

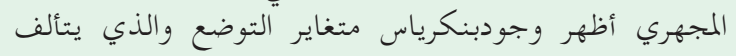

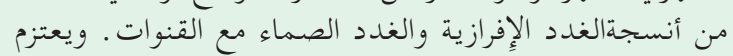

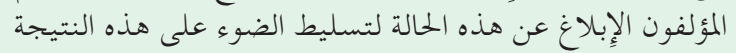

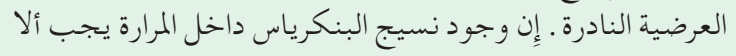

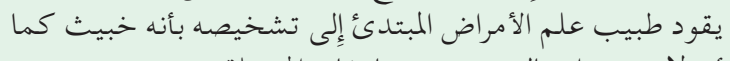

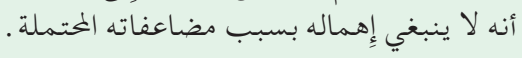

Heterotopic pancreas is defined as aberrantly located pancreatic tissue without anatomical, vascular, or neural connection to the pancreas. Usual sites include the stomach, duodenum, jejunum, and spleen; in rare cases, heterotopic pancreas can be found in the lungs, gallbladder, Meckel's diverticulum, and the mediastinum. In most cases, it is an insignificant, incidental finding. Pre-operative diagnosis is not possible, and histopathological examination is mandatory for establishing a definite diagnosis. Less than 40 cases of heterotopic pancreas in the gallbladder have been reported worldwide. Recently, a laparoscopic cholecystectomy specimen from a 43-year-old male showed a small nodule in the gallbladder neck. Microscopy revealed heterotopic pancreas composed of exocrine and endocrine glandular tissue with ducts. We report this case to highlight this rare, incidental finding. This condition should not cause pathologists to over diagnose such occurrences as malignancies; neither should they be neglected because they have potential complications.

Saudi Med J 2018; Vol. 39 (8): 834-837 doi:10.15537/smj.2018.8.22602
From the Department of Histopathology (Sharma, Makkawi, Abdalla), King Abdullah Hospital, Bisha, Kingdom of Saudi Arabia; and from the Department of Basic Medical Sciences (Sohail), College of medicine, University of Bisha, Bisha, Kingdom of Saudi Arabia.

Received 3rd April 2018. Accepted 14th June 2018.

Address correspondence and reprint request to: Dr. Shahzada K. Sohail, Department of Basic Medical Sciences, College of medicine, University of Bisha, Bisha, Kingdom of Saudi Arabia. E-mail: sks190@hotmail.com ORCID ID: orcid.org/0000-0002-7286-8074.

Opar horistoma in the form of ectopic or heterotopic ${ }_{\text {pancreas is an embryological abnormality and }}$ is defined as aberrantly located pancreatic tissue without anatomical, vascular, or neural connection to the pancreas. ${ }^{1,2}$ The sites usually involved include the stomach, duodenum, jejunum, and spleen; however, heterotopic pancreas is rarely encountered at other sites including the ileum, mesentery, lungs, gallbladder, liver, bile ducts, Meckel's diverticulum and the mediastinum. ${ }^{3,4}$ In most cases, the condition is an incidental finding during autopsy or laparotomy for unrelated reasons. However, heterotopic pancreas has the potential to lead all the metaplastic and neoplastic conditions that affect orthotropic pancreas. ${ }^{4}$ Preoperative diagnosis is not possible, and histopathological examination is mandatory for establishing a definite diagnosis. ${ }^{1,2}$ The incidence of heterotopic pancreas at all sites ranges from $0.55 \%-13.7 \%$ in autopsies and $0.2 \%$ in laparotomies. ${ }^{1,5,6} \mathrm{~A}$ number of cases have been reported in which heterotopic pancreatic tissue was incidentally found during microscopic examination of gallbladders after cholecystectomies for polyps, nodules, and acute or chronic cholecystitis with or without gallstones. ${ }^{1,2,3,5,6}$ The clinical significance of such incidental findings is still unclear. ${ }^{2,5}$ Here, we present a case study of heterotopic pancreatic tissue in the gallbladder to familiarize pathologists with the

Disclosure. Authors have no conflict of interests, and the work was not supported or funded by any drug company. 
condition and to stress that it should be considered in differential diagnosis of polyps, nodules and acalculous cholecystitis. Moreover, the microscopic appearance should not lead to over diagnosis of malignancy, nor should one overlook the condition as an insignificant incidental finding, considering its potential for sinister pathologies.

Case Report. Patient's information. A 43-year-old male presented to the Department of General Surgery, King Abdullah Hospital, Bisha, Saudi Arabia.

Clinical findings. Our patient presented with history of mild yellowish discoloration of the sclera and skin and fatty dyspepsia that was aggravated after meals. On physical examination tenderness was noted in the right upper abdomen; however, associated guarding or rebound tenderness was not present, no other significant past medical or surgical history was present.

Diagnostic assessment. Laboratory results showed alkaline phosphatase, $102 \mathrm{U} / \mathrm{L}$ (40-129 U/L); gamma glutamyl transferase, $75 \mathrm{U} / \mathrm{L}$ (8-61 U/L); total bilirubin, $22.9 \mu \mathrm{mol} / \mathrm{L} \quad(0-18.1 \mu \mathrm{mol} / \mathrm{L})$; and conjugated bilirubin, $9 \mu \mathrm{mol} / \mathrm{L}(0-7 \mu \mathrm{mol} / \mathrm{L})$ in patient's serum. These findings were consistent with clinical picture of obstructive jaundice. Serum amylase level was $96 \mathrm{U} / \mathrm{L}$ (normal range: $28-100 \mathrm{U} / \mathrm{L}$ ). Serum lipase was $139 \mathrm{U} / \mathrm{L}$ (normal range: 13-60 U/L). Abdominal ultrasound revealed multiple tiny stones, biliary sludge in the lumen of the gallbladder, and minimal wall edema. On magnetic resonance cholangiopancreatography (MRCP) multiple small gallbladder stones with a normal biliary tree were reported. A preoperative diagnosis of chronic cholecystitis with obstructive jaundice was made.

Therapeutic intervention. The pain and jaundice responded to conservative medical therapy, however laparoscopic cholecystectomy was carried out to prevent further episodes.

Histopathology and diagnosis. Macroscopic examination revealed a gallbladder measuring $75 \mathrm{~mm}$ into $25 \mathrm{~mm}$. The average wall thickness was $3 \mathrm{~mm}$. The mucosa showed focal ulceration and a single solid, whitish, intramural nodule measuring $6 \mathrm{~mm}$ in the neck region. Thick biliary sludge and multiple small stones were present in the lumen. Multiple representative sections were submitted for analysis.

Microscopic examination of the sections from the gallbladder neck revealed a well-circumscribed, intramural nodule of aberrant pancreatic tissue. Both exocrine and endocrine pancreatic tissues were present, consisting of acini and ducts along with a few islets of Langerhans (Figure 1). Our case was classified as type I according to the von Heinrich classification of pancreatic heterotopia. The remainder of the section showed chronic inflammatory reaction with epithelial changes consistent with chronic cholecystitis. No evidence of dysplasia or malignancy was found in any of the sections examined.

Follow-up. A smooth, uneventful recovery followed the surgery, and none of the symptoms persisted. No complication has been reported so far.

(Figure 2) represents the timeline from patient's presentation to final outcome.

Discussion. Pancreatic heterotopia is a rare anomaly that is mostly found in the stomach and duodenum. ${ }^{1-3}$ The gallbladder is an extremely rare location for heterotopic pancreas. ${ }^{1-3,5,7}$ The first reported case of heterotopic pancreas in the gallbladder dates
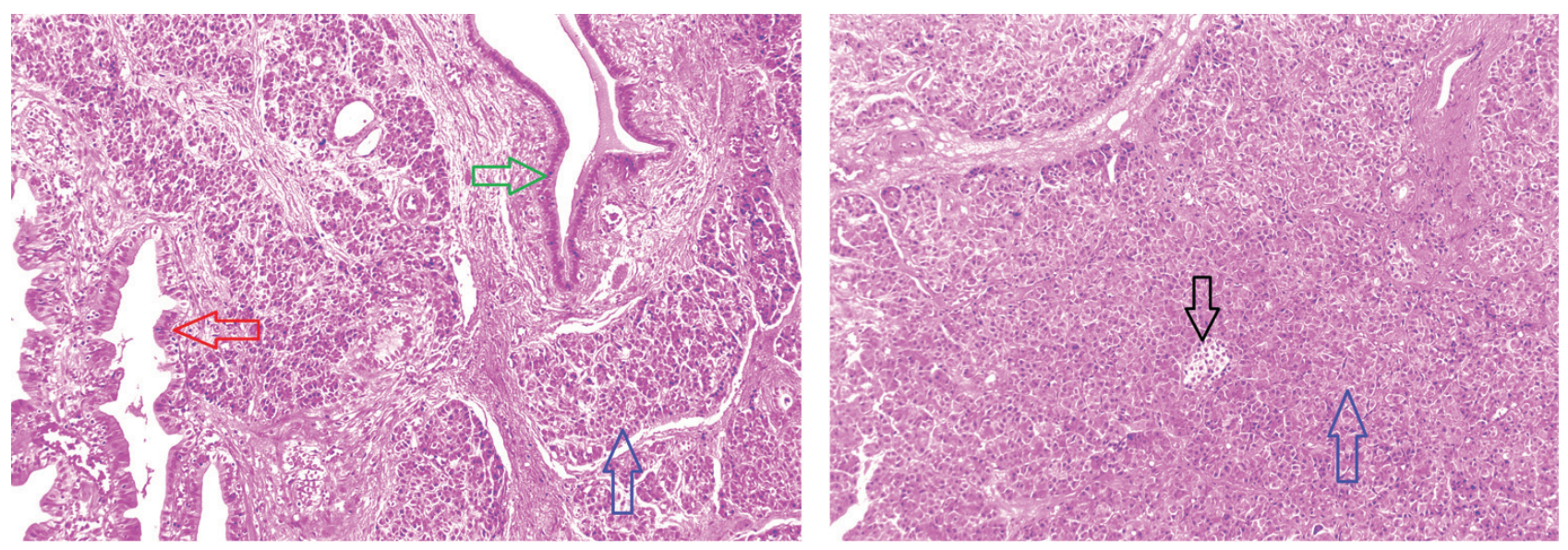

Figure 1 - Heterotropic pancreas in gallbladder (hematoxylin and eosin stain, 10X) showing: surface epothelium of gallbladder (red arrow), pancreatic acini (blue arrow), pancreatic duct (green arrow), and islet of langerhans (black arrow). 


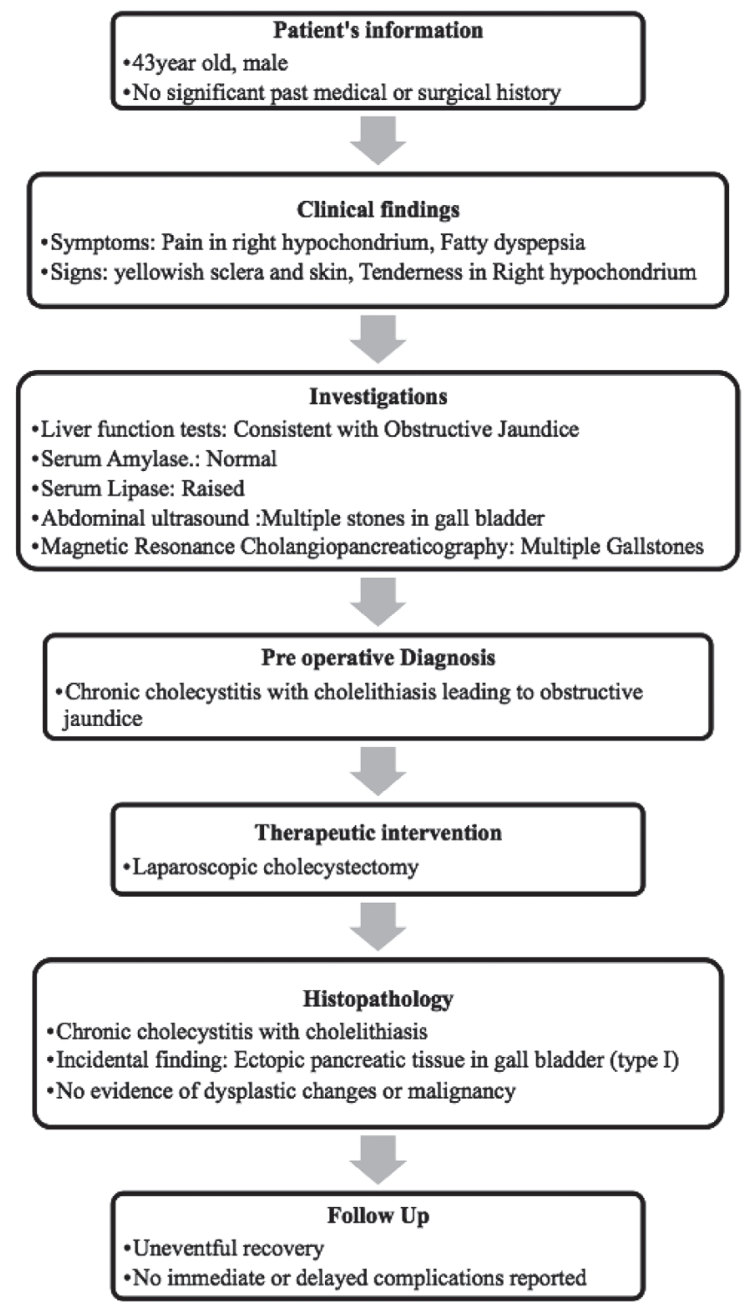

Figure 2 - Timeline summarizing the patient's information, clinical findings, investigations, preoperative diagnosis, therapeutic intervention, histopathology, and follow up.

back to 1916 in a description by Otschkin. ${ }^{2}$ So, far less than 40 cases of such occurrence have been reported. ${ }^{7}$ It is usually an incidental finding during autopsies or laparotomies due to unrelated reasons. The overall incidence ranges from $0.55 \%-13.7 \%$ in autopsies and $0.2 \%$ in laparotomies. ${ }^{1,5}$

Different theories have been proposed for the origin of this aberrant tissue at unusual sites. The most widely accepted hypothesis is that the tissue becomes separated from the developing pancreas during rotation of the gastrointestinal tract during the embryonic period. ${ }^{2,3}$

Macroscopically, these lesions can present as thickenings, nodule forms, or as a polyp. The tissue is located in the neck region of the gallbladder in half the
Table 1 - Modified Von Heinrich classification of ectopic pancreas. ${ }^{5,7}$

\begin{tabular}{|c|c|c|c|}
\hline Type 1 & Type 2 & Type 3 & Type 4 \\
\hline $\begin{array}{l}\text { Ectopic tissue } \\
\text { with acini, } \\
\text { ducts, and islets } \\
\text { of langerhans }\end{array}$ & $\begin{array}{c}\text { Canalicular } \\
\text { variant with } \\
\text { pancreatic ducts }\end{array}$ & $\begin{array}{c}\text { Exocrine } \\
\text { pancreas with } \\
\text { acinar tissue } \\
\text { only. No } \\
\text { endocrine tissue }\end{array}$ & $\begin{array}{c}\text { Endocrine } \\
\text { pancreas with } \\
\text { cellular islets } \\
\text { only. No } \\
\text { exocrine tissue }\end{array}$ \\
\hline
\end{tabular}

patients, as in our case. ${ }^{2,5}$ Histologically, exocrine and endocrine tissues can be present in various proportions. Von Heinrich classified pancreatic heterotopia into 3 groups in $1909 .^{2}$ later this classification was modified by Fuentes in 1973 (Table 1). 5,7 Accordingly, our case was classified as Type I.

Pancreatic heterotopia can occur at any age, but it is most often found in the 4th-6th decade of life. ${ }^{1}$ Overall, men are affected 3-5 times more frequently than women. ${ }^{2}$ However, when the site of ectopic pancreatic rests is the gallbladder, the patient is usually a female. ${ }^{1,2}$ This is probably due to the greater number of cholelithiaisis-related cholecystectomies in female patients. Our patient was a male in his 5 th decade.

The majority of cases are asymptomatic, and histologically discovered tissue is usually benign. However, heterotopic tissue can cause symptoms related to its location; such symptoms include jaundice due to obstruction of the bile duct, cholelithiasis, cholecystitis, intussusception and gastrointestinal hemorrhage. ${ }^{3,4}$ Although ectopic pancreas is usually found incidentally, it nonetheless has the potential to develop all of the metaplastic and neoplastic changes that occur in normally located pancreas, including acute or chronic pancreatitis, cyst formation, calcification, pancreatic cancers, and endocrine tumors. ${ }^{1,3,4}$ Therefore, complete excision of incidentally found pancreatic tissue is the treatment of choice. In cases of heterotopic pancreatic rests in the gallbladder, cholecystectomy is adequate..$^{2,3}$ As there are only a few such reported cases, the clinical and radiological features are not well defined. ${ }^{6}$ Preoperative diagnosis of this rare finding is not possible due to nonspecific features, and definitive diagnosis is only possible by histopathological examination. ${ }^{1,5}$

In conclusion, pancreatic heterotopia is a rare entity, when it is located in the gallbladder wall. Pathologists should be familiar with this rare, incidental finding, as it can mimic a tumor and lead to over diagnosis of malignancy. However, a careful examination is needed to rule out potential complications and related sinister pathologies. 


\section{References}

1. Bau PC, Lucchese A, Hohmann FB, Da Silva VD, Marcal JM. Ectopic pancreatic tissue in a gallbladder. SOJ 2016; 3: 1-2.

2. Marcano AJL, Gonzales JD, Ramia JM, Alonso S, Kuhnhardt A, Perna C, et al. Heterotopic pancreatic tissue in gallbladder. Arch Clin Exp Surg 2016; 5: 250-253.

3. Al-Shraim M, Rabie ME, Elhakeem H, Kandeel A, Shah MT, Jamil S. Pancreatic heterotopia in the gallbladder associated with chronic cholecystitis: a rare combination. JOP 2010; 11: 464-466.
4. Filip R, Walczak E, Huk J, Radzki RP, Bieńko M. Heterotopic pancreatic tissue in the gastric cardia: a case report and literature review. World J Gastroenterol 2014; 20: 16779-16781.

5. Sanchiz Cárdenas EM, Soler Humanes R, Lavado Fernández AI, Díaz Nieto R, Suárez Muñoz MA. Ectopic pancreas in gallbladder. Clinical significance, diagnostic and therapeutic implications. Rev Esp Enferm Dig 2015; 107: 701-703.

6. Basrur GB, Utture SK, Deshpande AA. Heterotopic pancreas in the gallbladder. Indian J Surg 2016; 78: 429-430.

7. Koukourakis IM, Perente Memet MS, Kouroupi M, Simopoulos K. Ectopic pancreatic tissue adherent to the external gallbladder wall. Case Rep Gastroenterol 2018; 12: 170-175. 